Supporting Information

\title{
Steric and Orbital Effects Induced by Iso-Valent Dopants on the Surface Chemistry of $\mathrm{ZrO}_{2}$
}

\author{
Farahnaz Maleki and Gianfranco Pacchioni* \\ Dipartimento di Scienza dei Materiali, Università di Milano-Bicocca, via R. Cozzi 55, 20125 \\ Milano, Italy
}

*E-mail address: gianfranco.pacchioni@unimib.it 
Table S1. The cation radius of $\mathrm{M}^{4+}$ dopants. ${ }^{1}$

\begin{tabular}{|l|c|c|}
\hline Cation & $\mathrm{R}\left(\mathrm{M}_{4 \mathrm{c}}\right), \AA$ & $\mathrm{R}\left(\mathrm{M}_{6 \mathrm{c}}\right), \AA$ \\
\hline $\mathrm{Si}^{4+}$ & 0.26 & 0.40 \\
\hline $\mathrm{Ge}^{4+}$ & 0.39 & 0.53 \\
\hline $\mathrm{Sn}^{4+}$ & 0.55 & 0.69 \\
\hline $\mathrm{Pb}^{4+}$ & 0.65 & 0.78 \\
\hline $\mathrm{Ti}^{4+}$ & 0.42 & 0.61 \\
\hline $\mathrm{Zr}^{4+}$ & 0.59 & 0.72 \\
\hline $\mathrm{Hf}^{4+}$ & 0.58 & 0.71 \\
\hline $\mathrm{Ce}^{4+}$ & - & 0.87 \\
\hline
\end{tabular}

1. Haynes, W. M. (Ed.) (2014). CRC handbook of chemistry and physics. CRC press. 
Figure S1. Density of states (DOS) of pristine and doped t- $\mathrm{ZrO}_{2}$ surfaces.

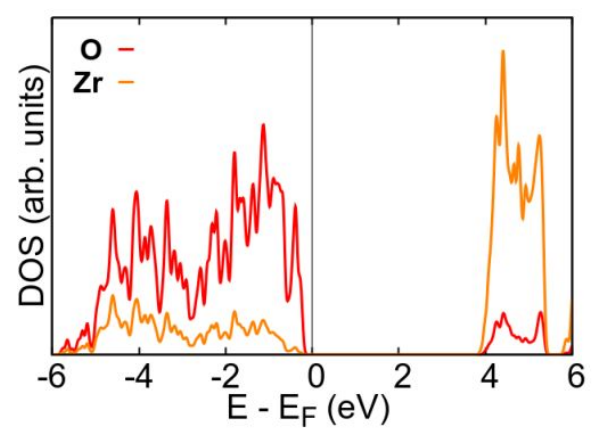

a) pristine $\mathrm{ZrO}_{2}$

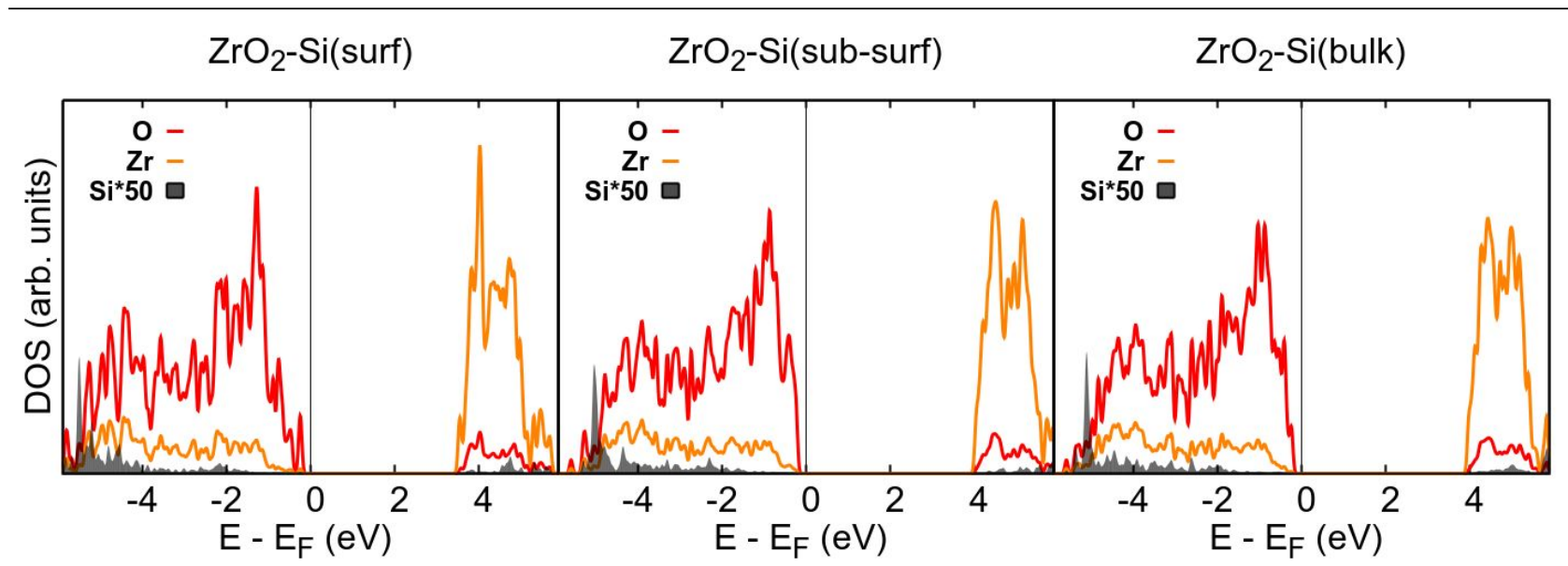

b)

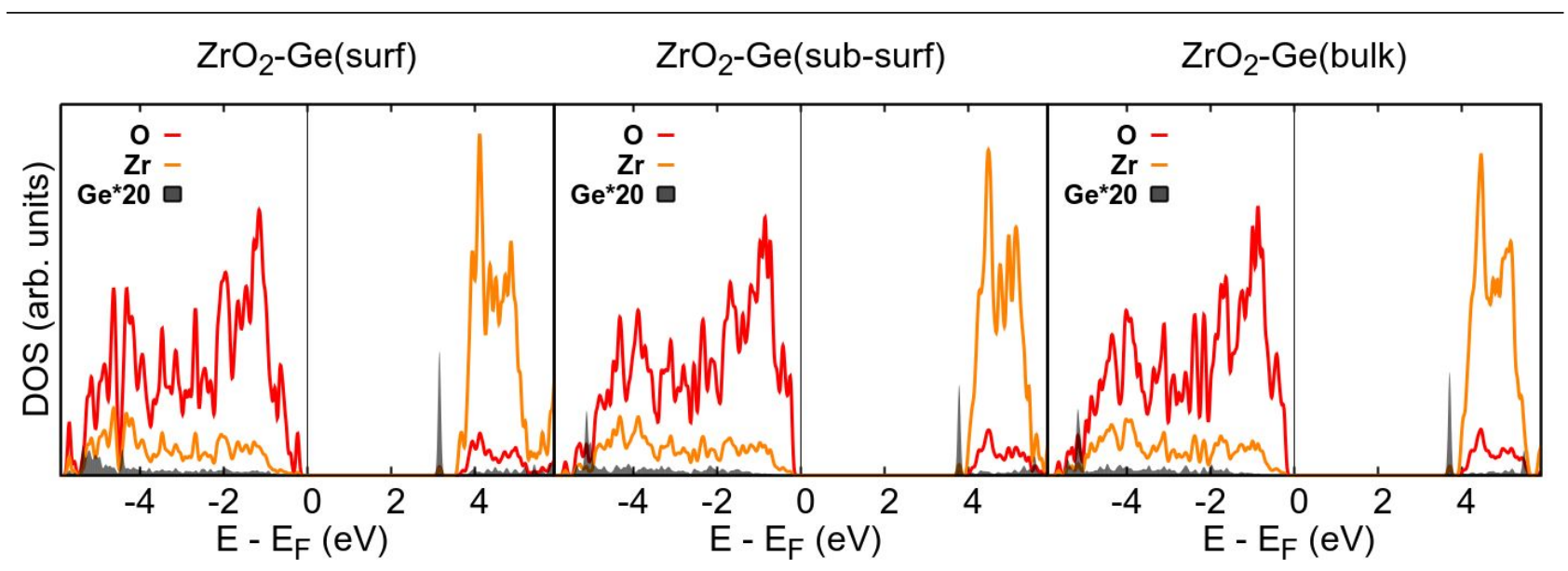

c) 


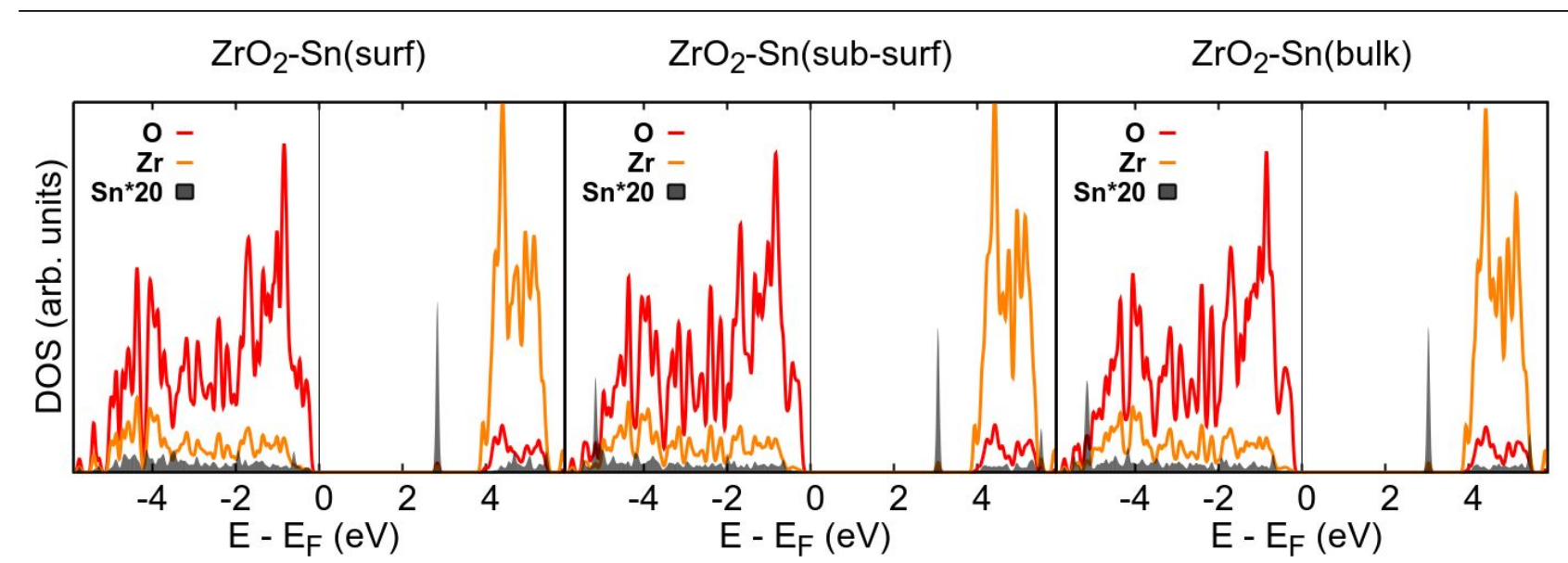

d)

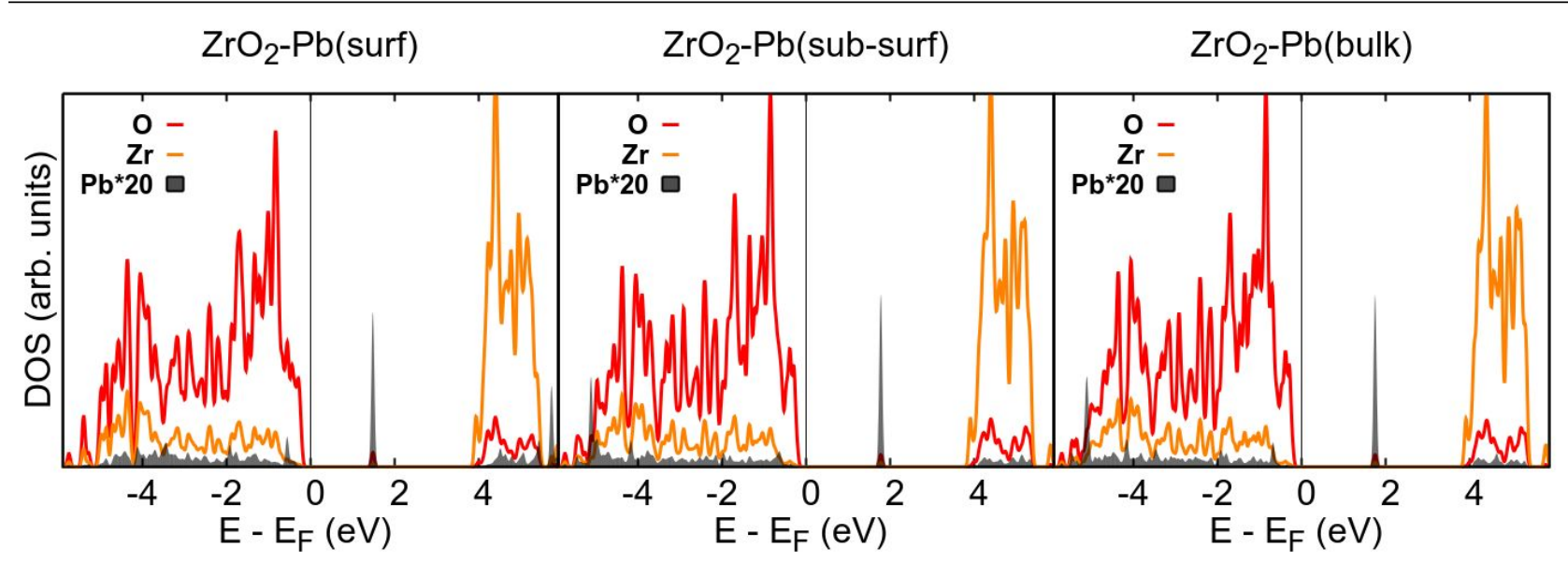

e)

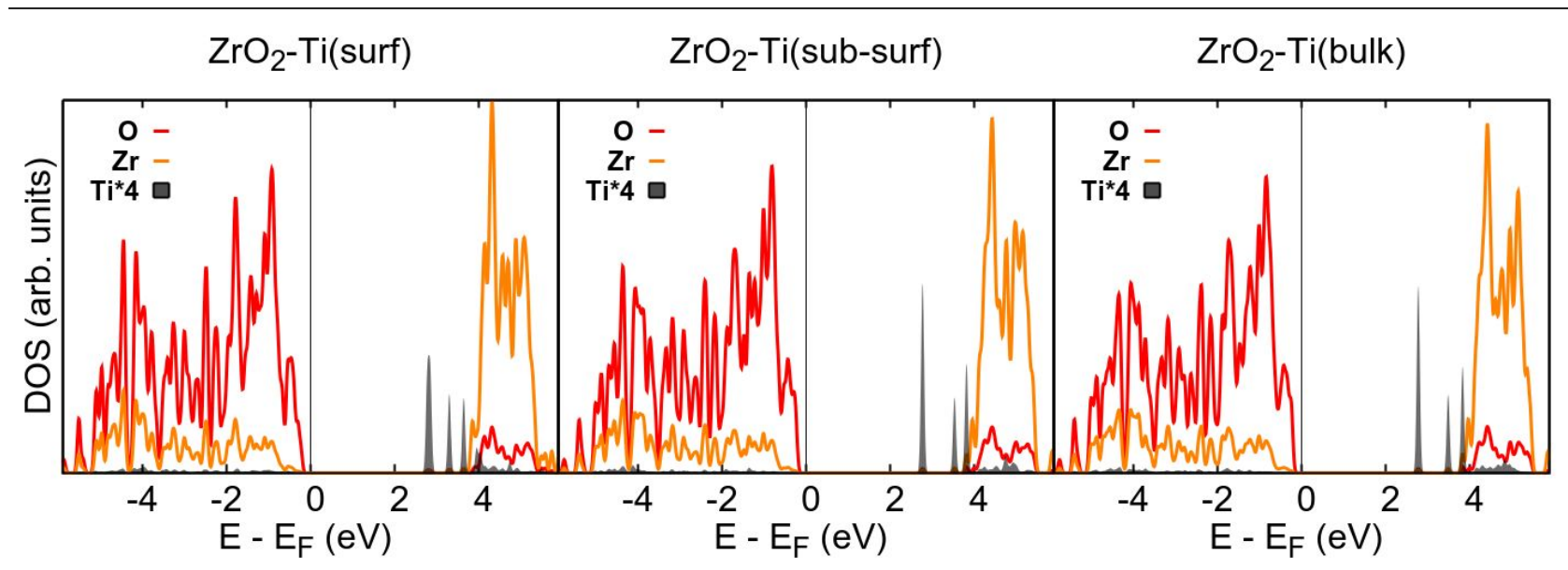

f) 


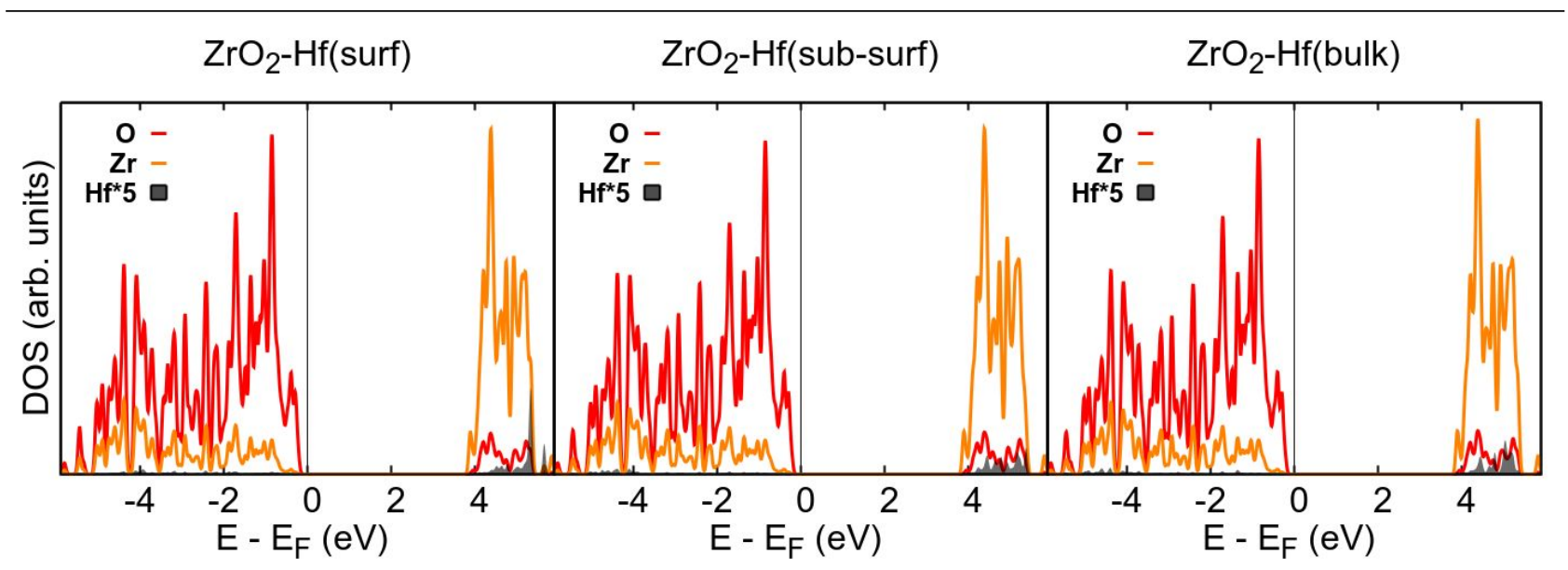

g)

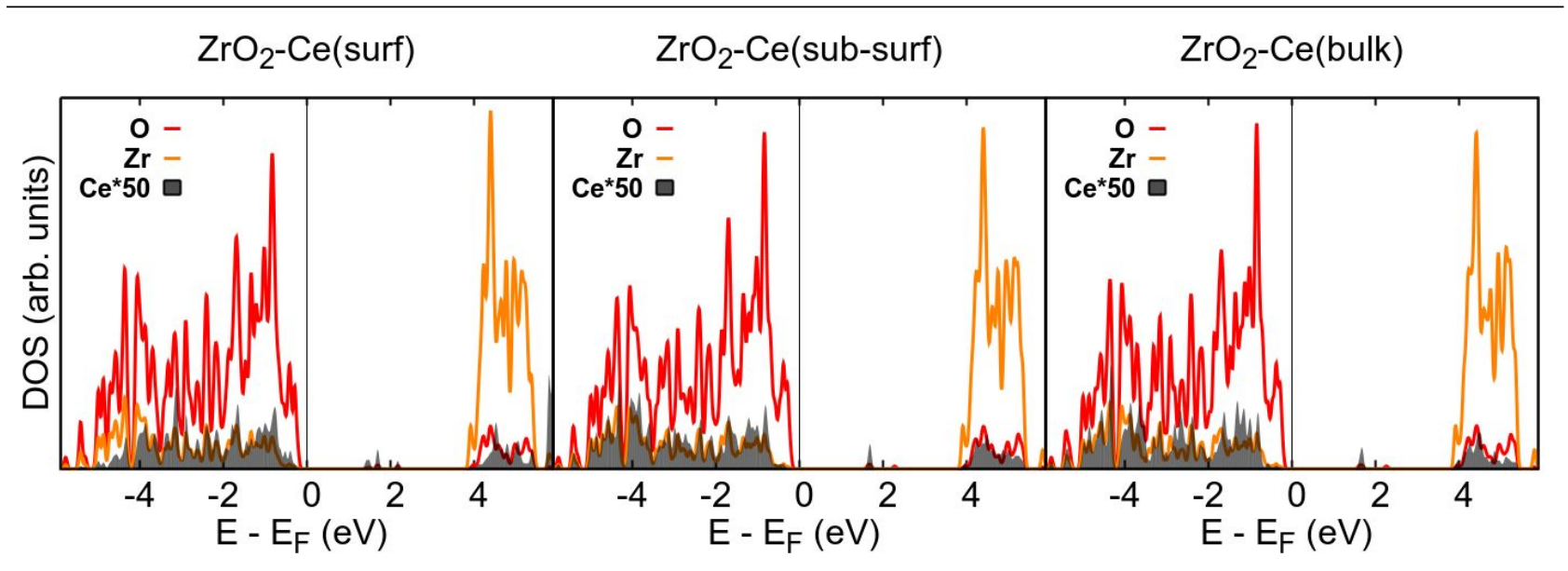

h) 

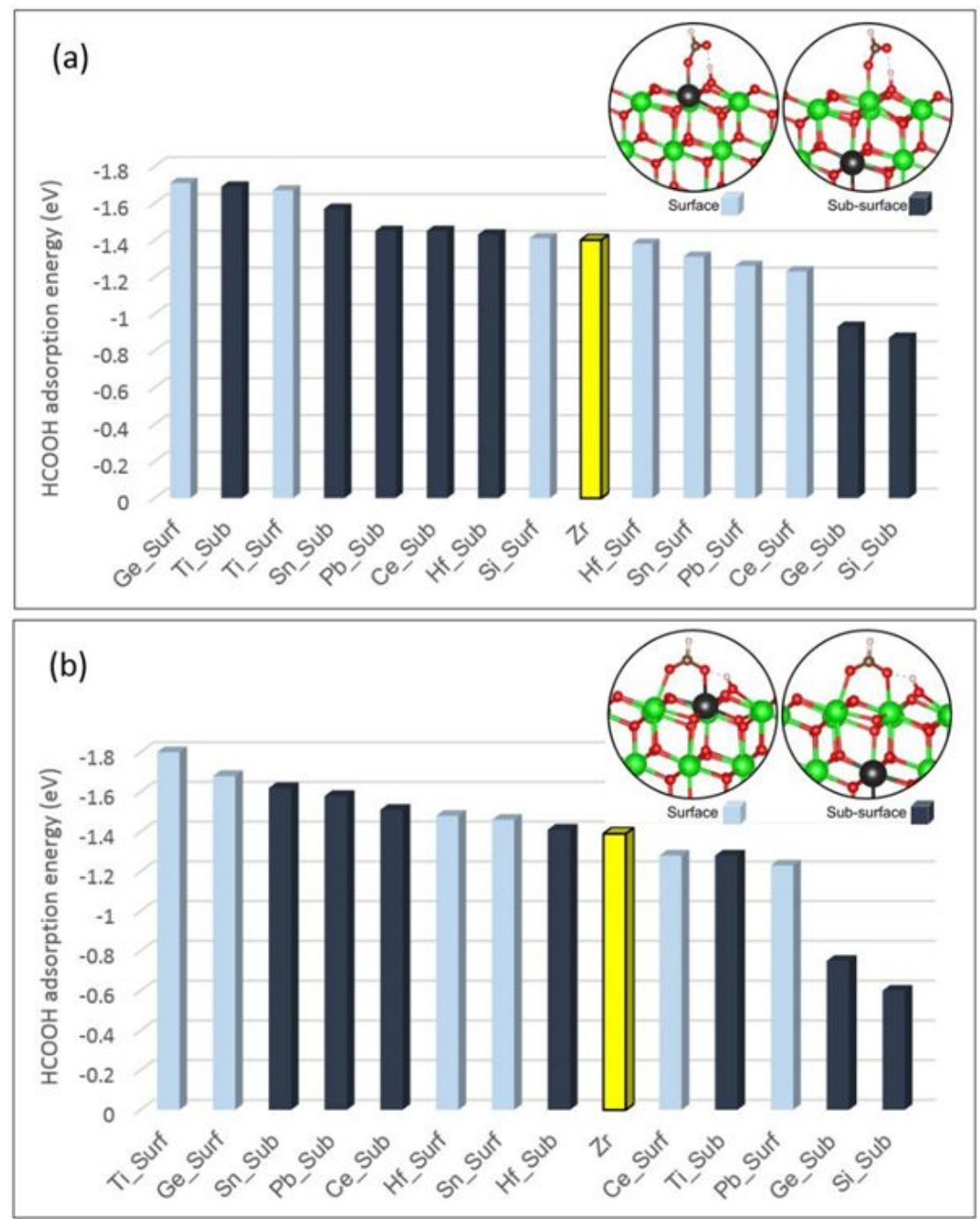

Figure S2. Graphic representation of adsorption energies of (a) monodentate, and (b) bidentate $\mathrm{HCOOH}$ on pristine and doped $\mathrm{ZrO}_{2}$ surfaces. 

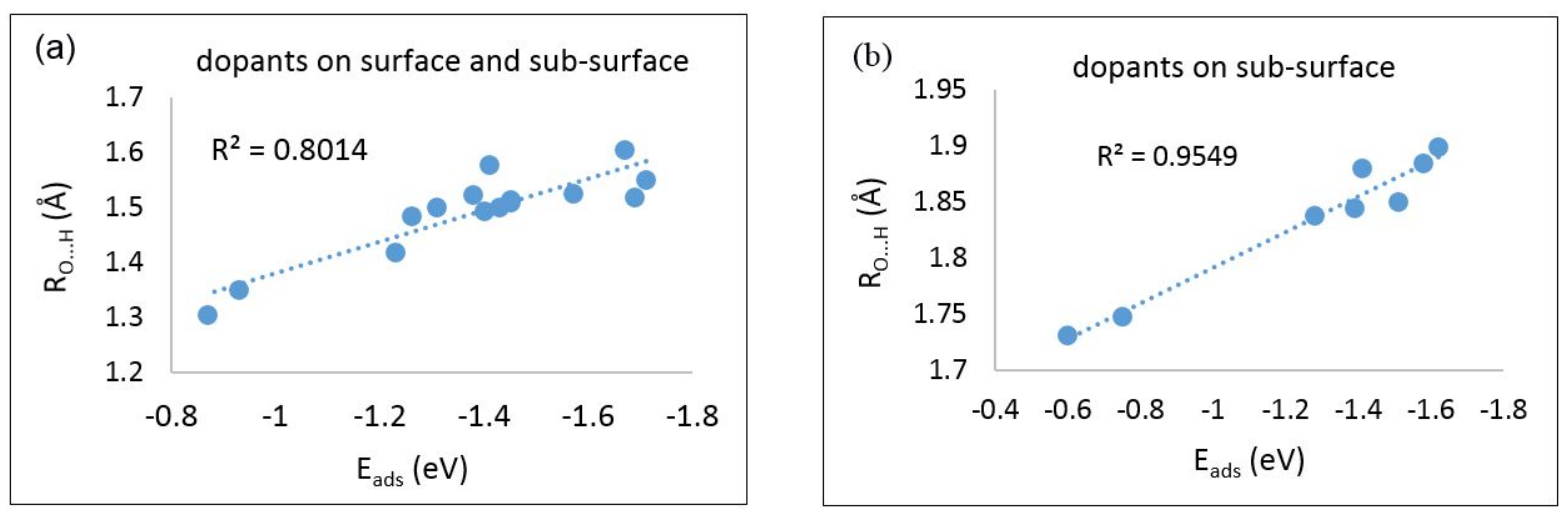

Figure S3. (a) Correlation between adsorption energy, $E_{a d s}(e V)$, and the length of the hydrogen bond ( $\left.\mathrm{R}_{\mathrm{O}-\mathrm{H}}, \AA\right)$ for monodentate formic acid, Fig 4(a), for pristine and doped $\mathrm{ZrO}_{2}$ surfaces; (b) Correlation between adsorption energy, $\mathrm{E}_{\mathrm{ads}}, \mathrm{eV}$, and hydrogen bond distance $\left(\mathrm{R}_{\mathrm{O}-\mathrm{H}}, \AA\right)$ for bidentate formic acid, Fig. 4(b), for pristine and doped $\mathrm{ZrO}_{2}$ surfaces. 

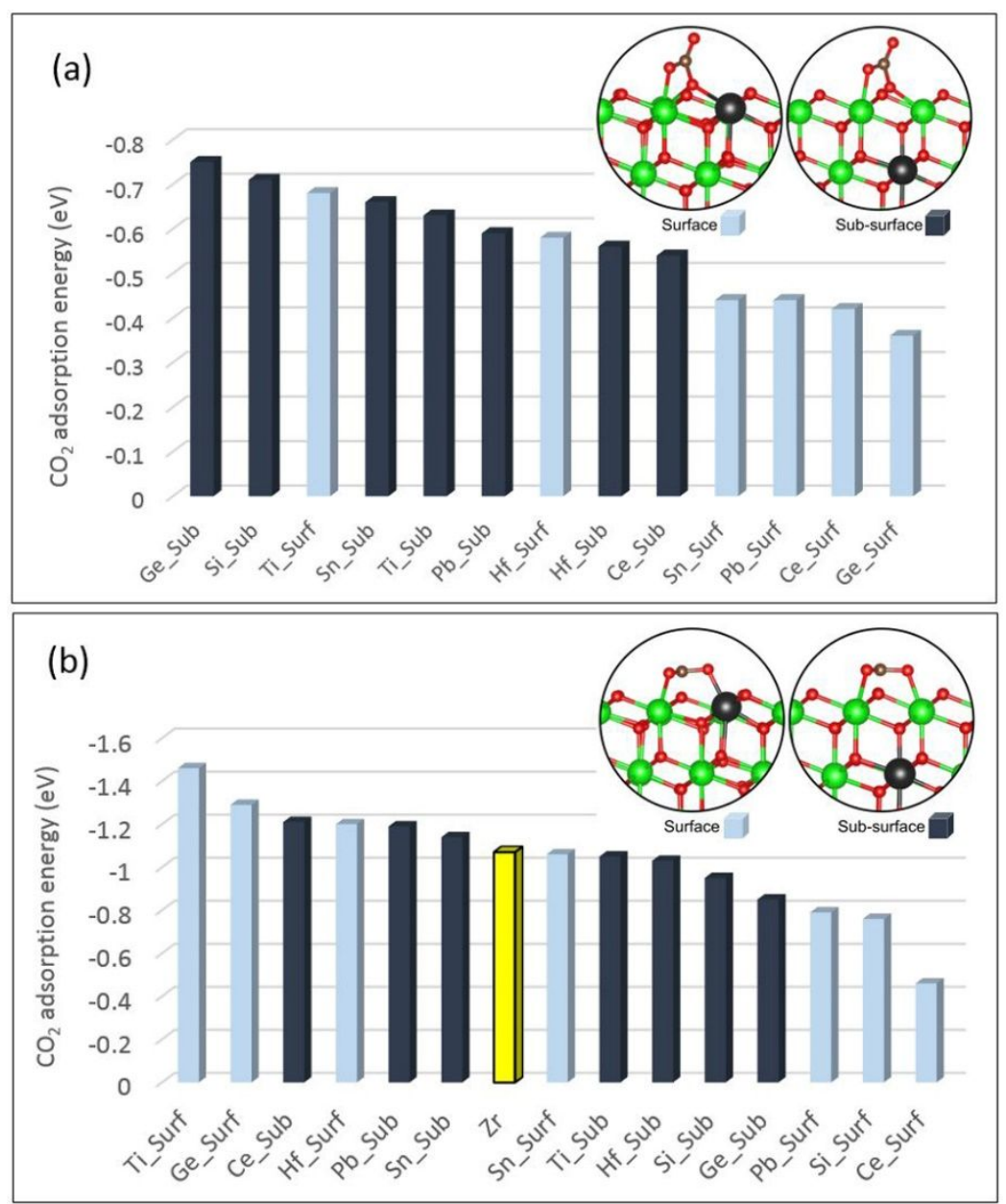

Figure S4. Graphic representation of adsorption energies of (a) "normal", and (b) "parallel" $\mathrm{CO}_{2}$ on pristine and doped $\mathrm{ZrO}_{2}$ surfaces. 


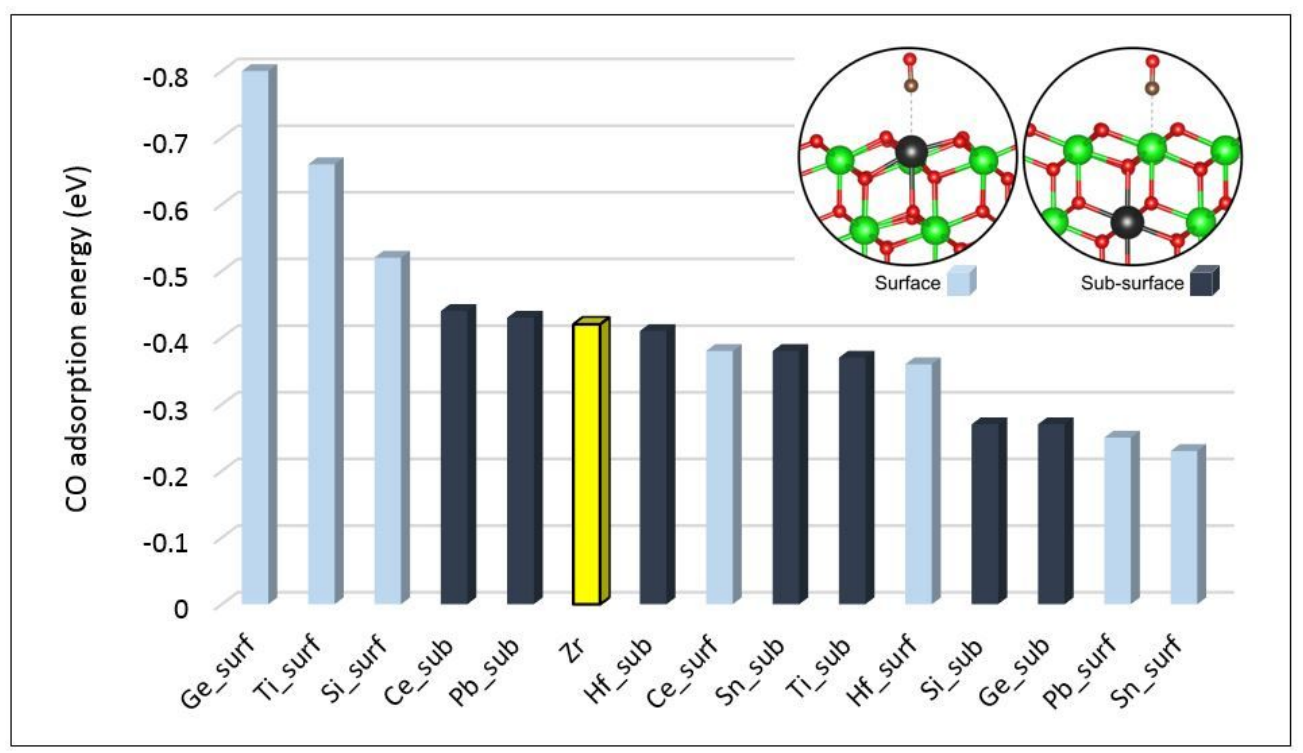

Figure S5. Graphic representation of $\mathrm{CO}$ adsorption energy on pristine and doped $\mathrm{ZrO}_{2}$ surfaces. 

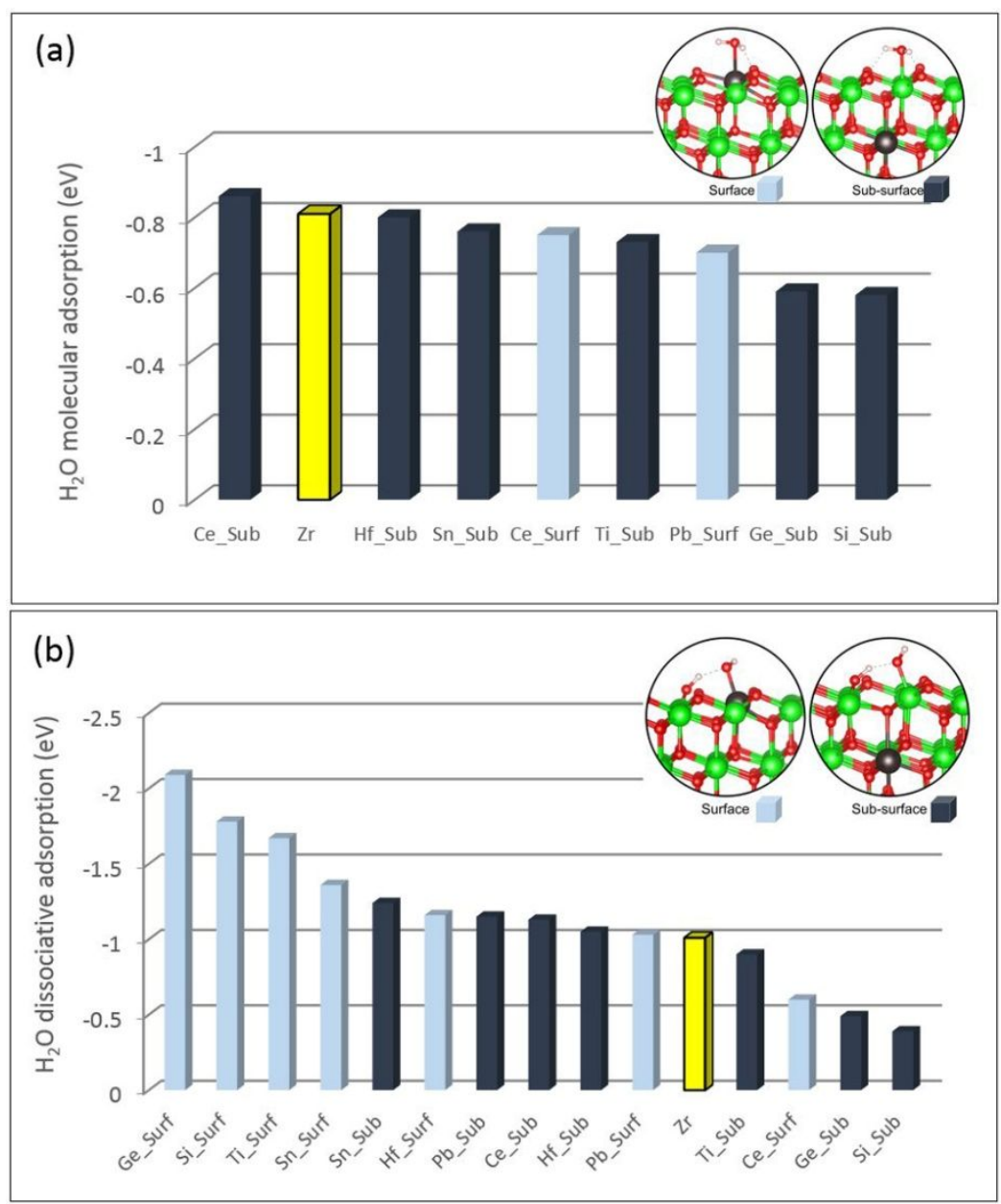

Figure S6. Graphic representation of molecular (a) and dissociative (b) water adsorption on pristine and doped $\mathrm{ZrO}_{2}$ surfaces. 

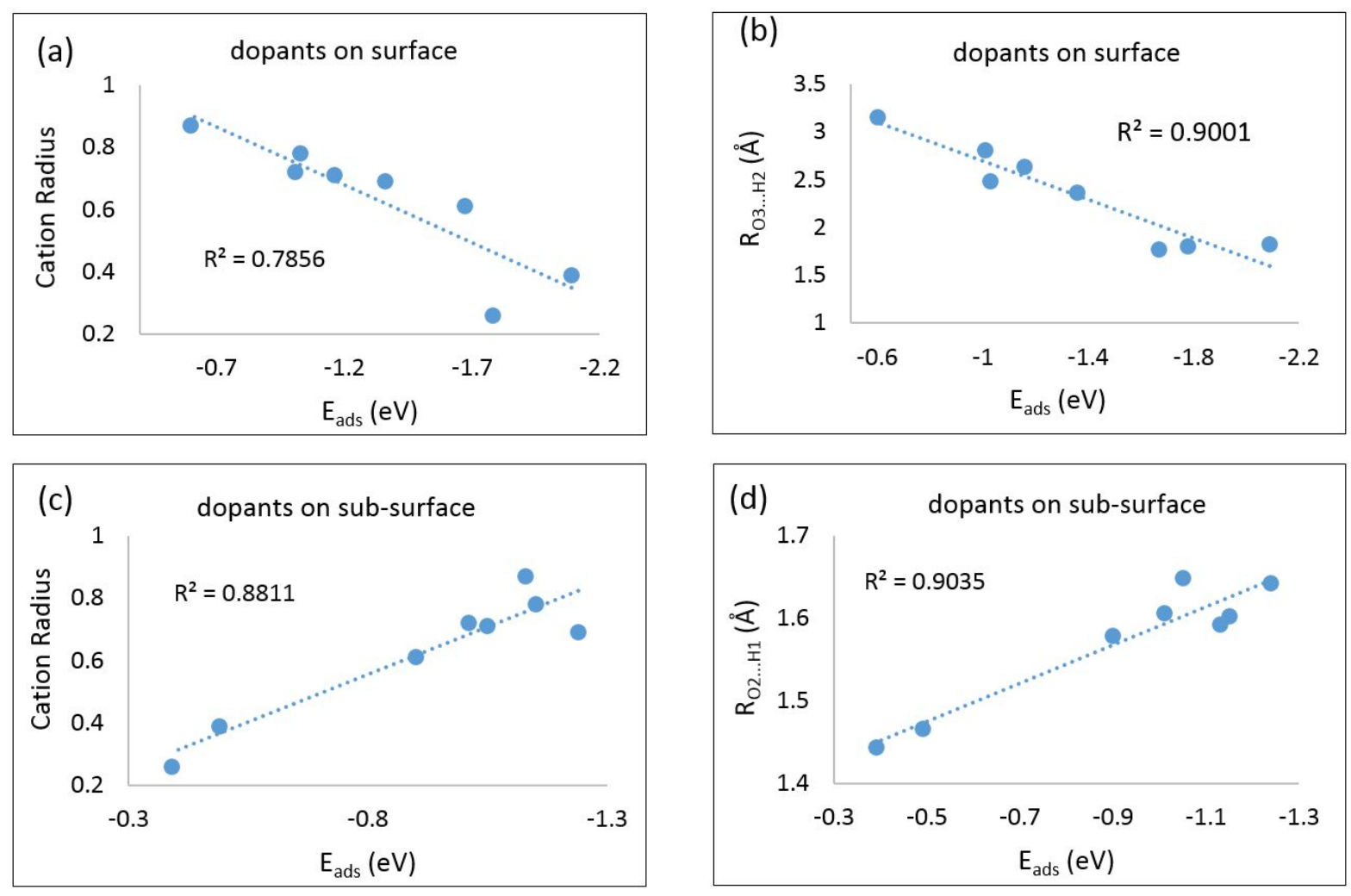

Figure S7. (a) Surface dopants: Correlation between the energy of dissociative water adsorption $\left(\mathrm{E}_{\mathrm{ads}}, \mathrm{eV}\right)$ and cation size of $\mathrm{M}^{4+}: 4 \mathrm{c}(\mathrm{Si}$ and $\mathrm{Ge})$ and $6 \mathrm{c}(\mathrm{Sn}, \mathrm{Pb}, \mathrm{Ti}, \mathrm{Zr}, \mathrm{Hf}, \mathrm{Ce})$ on pristine and doped $\mathrm{ZrO}_{2}$ surfaces; (b) Surface dopants: Correlation between the energy of dissociative water adsorption $\left(\mathrm{E}_{\mathrm{ads}}, \mathrm{eV}\right)$ and $\mathrm{R}_{\mathrm{H} 2-\mathrm{O} 3}(\AA)$ on pristine and doped $\mathrm{ZrO}_{2}$ surfaces; (c) Sub-surface dopants: Correlation between the energy of dissociative water adsorption $\left(\mathrm{E}_{\mathrm{ads}}, \mathrm{eV}\right)$ and cation size of $\mathrm{M}^{4+}$ : 4c ( $\mathrm{Si}$ and $\mathrm{Ge}$ ) and 6c ( $\mathrm{Sn}, \mathrm{Pb}, \mathrm{Ti}, \mathrm{Zr}, \mathrm{Hf}, \mathrm{Ce}$ ) on pristine and doped $\mathrm{ZrO}_{2}$ surfaces. (d) Sub-surface dopants: Correlation between the energy of dissociative water adsorption $\left(\mathrm{E}_{\mathrm{ads}}, \mathrm{eV}\right)$ and $\mathrm{R}_{\mathrm{O} 2-\mathrm{H} 1}(\AA)$ on pristine and doped $\mathrm{ZrO}_{2}$ surfaces. 
(a) $\mathrm{Ti}: \mathrm{ZrO}_{2}$

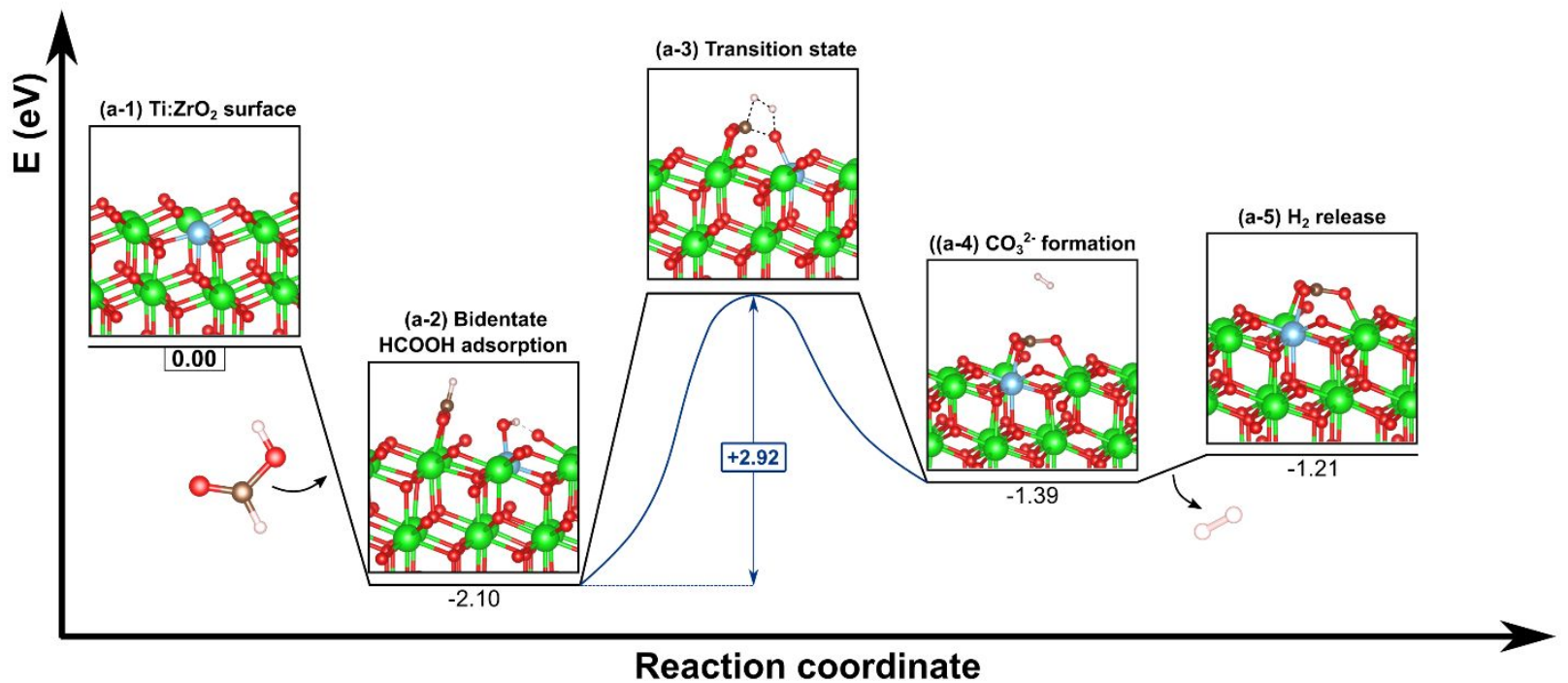

(b) $\mathrm{Ce}: \mathrm{ZrO}_{2}$

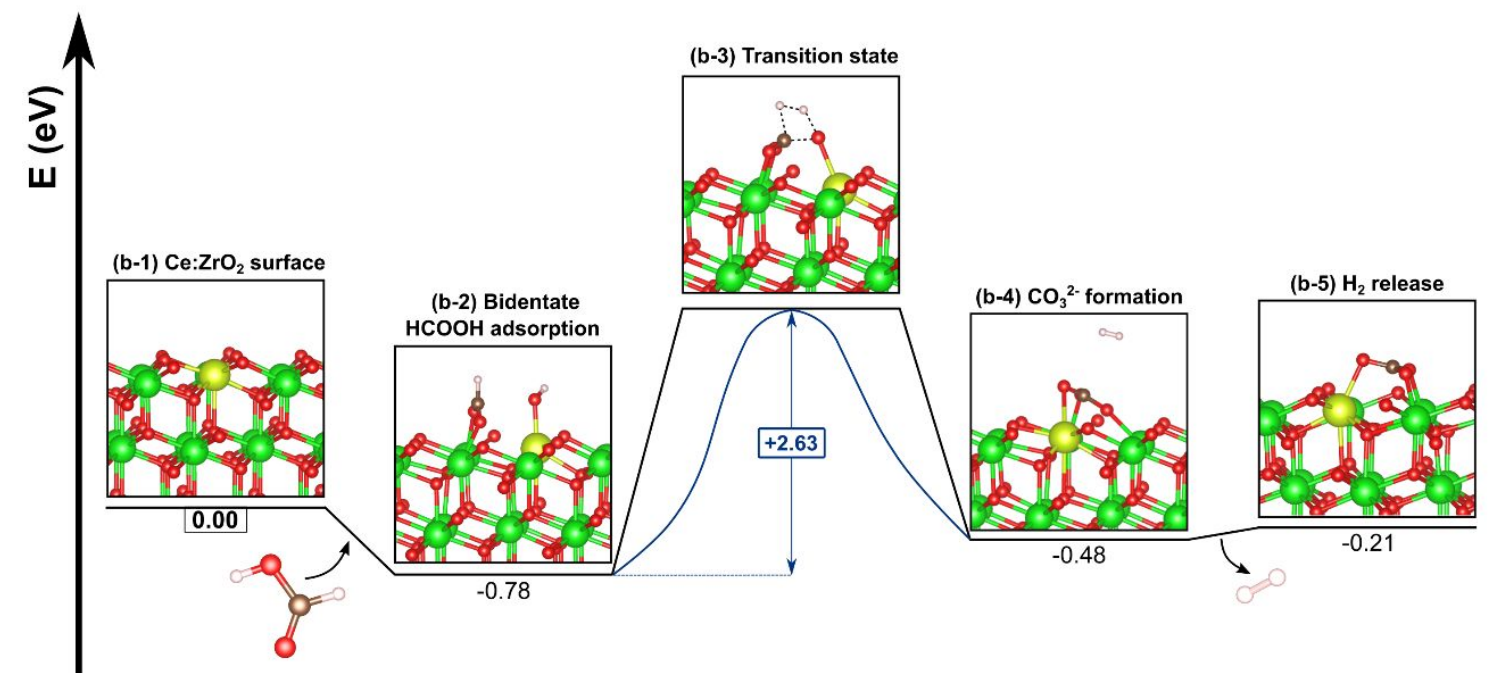

\section{Reaction coordinate}

Figure S8. Energy profile and activation barrier for the dehydrogenation reaction of formic acid on (a) Ti: $\mathrm{ZrO}_{2}$ and (b) $\mathrm{Ce}: \mathrm{ZrO}_{2}$. With respect to the curves presented in Figure 10 of the paper, the $\mathrm{Ti}$ and $\mathrm{Ce}$ dopants are below the $\mathrm{OH}$ group and not involved with the bonding of the $\mathrm{HCOO}^{-}$ fragment. 